\title{
CULTURAS DA INFÂNCIA: A IMPORTÂNCIA DO LÚDICO NA EDUCAÇÃO INFANTIL
}

Carolline Rodrigues Guedes, Márcia Regina Canhoto de Lima, José Milton de Lima.

Universidade Estadual Paulista - UNESP. E-mail: carolguedes11@outlook.com

Orgão de Fomento: CNPq.

\section{RESUMO}

Esta investigação teve como objeto de estudo a ludicidade e o professor no contexto da Educação Infantil. Assumiu como objetivo analisar como os professores concebiam as Culturas da Infância e como eles trabalhavam um dos eixos estruturadores dessas culturas: a ludicidade. A pesquisa desenvolveu-se em duas salas de Educação Infantil: I e II de uma instituição municipal de Presidente Prudente, contou com cinquenta e cinco crianças e duas professoras. A investigação surgiu a partir da constatação de que alguns professores desconhecem ou ignoram a importância das Culturas da infância. Os referenciais predominantes da pesquisa foram os estudos da Sociologia da Infância. A metodologia utilizada foi de natureza qualitativa e caracterizou-se como pesquisa do tipo etnográfico. Os resultados coletados revelaram que as educadoras compreendiam a importância do brincar em sala de aula. Entretanto, em algumas observações, predominou a desvalorização da ludicidade e da imaginação dos alunos por parte de algumas professoras.

Palavras-chave: Culturas Infantis, Sociologia da Infância, Educação Infantil, Ludicidade, Formação de professores.

\section{CULTURES OF CHILDHOOD: THE IMPORTANCE OF PLAYFULNESS IN EARLY CHILDHOOD EDUCATION}

\begin{abstract}
This research had as object of study the playfulness and the teacher in the context of Early Childhood Education. It aimed to analyze how teachers conceived the cultures of childhood and how they worked one of the structuring axes of these cultures: playfulness. The research was carried out in two rooms of Infantile Education: I and II of a municipal institution of Presidente Prudente, counted on fifty five children and two teachers. The research emerged from the finding that some teachers are unaware or ignore the importance of childhood cultures. The predominant references of the research were the Sociology of Childhood studies. The methodology used was of a qualitative nature and was characterized as ethnographic research. The results collected revealed that the educators understood the importance of playing in the classroom. However, in some observations, there was a predominance of the devaluation of students' playfulness and imagination by some teachers.
\end{abstract}

Keywords: Children's cultures, Sociology of childhood, Early childhood education, Playfulness, Teacher training. 


\section{INTRODUÇÃO}

O lúdico tem se apresentado como uma temática de destaque em congressos, encontros e eventos da área educacional, assim como o número de publicações relacionadas ao brincar tem se intensificado. $O$ crescimento acerca dessa temática deu-se pelo fato das contribuições que podem ocorrer no desenvolvimento cognitivo, motor e social da criança.

Deste modo, assumimos a necessidade de investigar e ampliar a produção científica sobre a criança e sobre as culturas da infância, além de considerá-la como sujeito cultural e social. Para isso, tivemos como marco teórico a Sociologia da Infância, uma área do conhecimento que considera a criança como ator social pleno em seu desenvolvimento, um ser que produz culturas e é cheio de particularidades.

A presente pesquisa contou com uma ampla fundamentação teórica, visto que essa foi de suma importância no caminhar dos estudos para entender as questões relacionadas às culturas da infância, em especial a ludicidade, no contexto escolar.

A delimitação do problema dessa pesquisa surgiu a partir da constatação de que muitos professores não concebem as Culturas da Infância, principalmente o eixo ludicidade, foco dessa pesquisa, como um importante fator no desenvolvimento infantil, e fazem uso do lúdico apenas como um passatempo nas horas vagas.

Os objetivos da pesquisa foram: Identificar e compreender como são concebidas as culturas da infância em duas salas de Educação Infantil: I e II, em uma escola municipal e analisar como os professores trabalham o eixo "ludicidade" nessas duas turmas de Educação Infantil.

\section{METODOLOGIA}

Essa pesquisa buscou, primeiramente, reconhecer as crianças como sujeitos capazes de produzir cultura, ao invés de tratá-las como simples objetos de pesquisa, e, também, ressaltar a importância da valorização do lúdico pelos professores no contexto da Educação Infantil, já que esta é de suma importância no desenvolvimento das crianças.

A pesquisa é de natureza qualitativa, uma vez que não se limita apenas em dados quantitativos, mas aborda variedades técnicas com a finalidade de apreender e de interpretar os significados existentes no local de investigação, neste caso, a instituição parceira.

Por pesquisa qualitativa entendemos qualquer tipo de pesquisa que gera resultados que não foram alcançados por procedimentos estatísticos ou outro tipo de quantificação. Pode referir-se a pesquisa sobre a vida das pessoas, histórias, comportamentos e também ao funcionamento organizativo, aos movimentos sociais ou às relações e interações. (STRAUSS E CORBIN apud SANDÍN ESTEBAN, 2010, p. 124).

Apoiados no referencial qualitativo, utilizamos o procedimento técnico do tipo etnográfico. Esse procedimento não segue todos os princípios da etnografia, contudo faz uma adaptação deles para a realidade escolar.

A etnografia é um esquema de pesquisa desenvolvido pelos antropólogos para estudar a cultura e a sociedade. Etimologicamente etnografia significa "descrição cultural". Para os antropólogos o termo tem dois sentidos: (1) um conjunto de técnicas que eles usam para coletar dados sobre os valores, os hábitos, as crenças, as práticas e os comportamentos de um grupo social; e (2) um relato escrito resultante do emprego dessas técnicas (ANDRÉ, 1995, p. 27).

O pesquisador, ao entrar no mundo do sujeito e estabelecer uma relação com o grupo pesquisado, permite-se conhecer e aprender com as crianças. Desse modo, a pesquisa do tipo etnográfica favorece a compreensão das Culturas da Infância no contexto escolar.

[...] não como alguém que faz uma pequena paragem ao passar, mas como quem vai fazer uma visita; não como uma pessoa que sabe tudo, mas como alguém que quer aprender; não como uma pessoa que quer ser como o sujeito, mas como alguém que procura saber o que é ser como ele (BOGDAN E BIKLEN apud VIÉGAS, 2007, p. 104). 
O estudo etnográfico possibilita um contato "face a face" com a realidade escolar. André (1995) aponta que a etnografia permite que o pesquisador chegue bem perto da escola, entendendo seu cotidiano. Além disso, o pesquisador Marchi (2010, p. 194) diz que "a etnografia tem sido apontada como metodologia particularmente adequada ao imperativo de 'dar voz' às crianças fazendo-as participar na produção dos dados sociológicos sobre suas maneiras de ser, sentir, agir e pensar".

A coleta de dados foi feita em um diário de campo para facilitar o processo de sistematização dos mesmos. Neste diário, foram colocadas a data da observação, a turma, os nomes das crianças ${ }^{1}$, o espaço de realização das atividades, a temática do brincar e o envolvimento das crianças durante os momentos de brincadeira. Como procedimentos metodológicos, utilizamos a máquina fotográfica, as filmagens e as fotos, além de um questionário aplicado às professoras, a fim de [...] "aprofundar as questões e esclarecer os problemas observados" (ANDRÉ, 1995, p. 28).

As observações foram desenvolvidas às segundas-feiras, no período das $13 \mathrm{~h} 00$ às $15 \mathrm{~h} 00$, com duração de sessenta minutos em cada sala. Lembrando que, primeiramente, houve uma conversa com a diretora da escola, com o intuito de explicar os objetivos da pesquisa e de pedir permissão para desenvolvê-la no espaço escolar. Essa pesquisa foi autorizada pelo Comitê de Ética em Pesquisa com Seres Humanos, processo $n^{\circ}$ 102/2009.

\section{RESULTADOS}

Durante as observações, procuramos conduzir nosso olhar para as ações que envolviam a ludicidade nos diferentes espaços escolares. No primeiro dia de observação, apresentamo-nos às crianças e às professoras. Explicamos o porquê da nossa presença e o que iríamos fazer durante as observações. Para nos conhecermos melhor e interagirmos com as crianças e professoras, fizemos uma brincadeira.

No momento em que nos apresentamos às professoras, ao falar dos objetivos da pesquisa, dissemos que elas poderiam participar das atividades junto às crianças, dar opiniões quando quisessem e repetir as brincadeiras dadas pelos bolsistas, quando achassem necessário.

Percebemos, durante as observações, que as duas professoras, Judite e Sara, tiveram posturas diferentes. A professora Judite participou ativamente das atividades com as crianças. Enquanto a professora Sara, além de não participar, chamava a atenção dos alunos para que não conversassem e para que não corressem muito rápido para não se machucar.

Em outra observação, a professora Judite levou vários brinquedos para a quadra poliesportiva e, com isso, proporcionou aos alunos a imaginação e a ludicidade de uma maneira bastante significativa, pois ela "entrou" nas brincadeiras dos alunos, dando-lhes o prazer de brincar e aprender ao mesmo tempo.

$\mathrm{Na}$ quadra havia diversos brinquedos. Felipe estava brincando de cuidar de um bebê e disse ao boneco:

- Você vai tomar banho, tá bom?

Olhando a brincadeira, a professora Judite disse para Felipe:

- Lava direitinho, tem toalha? Não? Pera aí que eu vou pegar uma toalha e um sabonete!

Depois disso, a professora foi buscar um sabonete (de verdade), um perfume e uma toalha, e entregou ao aluno. Ele começou a dar banho nos bebês com as coisas que a professora Ihe entregou: fingiu jogar água, passou o sabonete no corpo do boneco e o enxugou com uma toalha e, em seguida, passou o perfume no boneco.

Um tempo depois, havia outro aluno brincando de fazer bolo com algumas panelinhas, e a professora Judite disse:

1 Todos os nomes transcritos nessa pesquisa são fictícios, para manter o sigilo dos participantes da pesquisa. 
- Faz um bolo Eduardo, aqui no forninho, coloca para assar, para nós comermos! Bem gostoso, capricha aí, hein!

Em seguida, a professora deu uma cozinha com um forno para o aluno continuar a brincadeira.

Nessa mesma observação, fizemos uma brincadeira em que as crianças deveriam fazer um círculo e ficar de pé com as mãos dadas. Nesse círculo, eles iriam passar um bambolê pelo corpo sem soltar as mãos dos colegas. A professora Judite logo entrou no círculo para fazer a brincadeira também, conforme acontecia a brincadeira, os alunos sentiam-se mais entusiasmados. No momento em que o bambolê chegava na professora, os alunos gritavam:

- Prô, você vai perder, prô, corre!

$\mathrm{E}$, em seguida, começaram a contar:

- Cinco, quatro, três, dois, um...

A professora corria para não "perder" a brincadeira, e os alunos se divertiam muito.

Em outra aula, pudemos notar a imaginação de uma aluna, durante uma brincadeira que foi desenvolvida por nós. Estávamos sentados com as crianças em cima de uma parte azul da quadra. Enquanto a colaboradora do projeto explicava a atividade, eu conversava com a aluna Ester:

Carol (bolsista): - Nós estamos em um grande rio.

Ester: - É, e nós não estamos afundando!

Carol: - Verdade, porque aqui é duro e não vamos afundar!

Ester: - Cuidado para não cair no rio, hein!

Em seguida, Ester colocou a mão tampando o nariz, e deitou no chão, dizendo:

- Que água gelada!

Conforme aconteciam as observações, era nítida a presença da professora Judite nas brincadeiras, pois ela participava e fazia parte das fantasias das crianças. A outra professora, Sara, não brincava com as crianças nas aulas e ficava olhando de longe, chamando a atenção dos alunos para que não bagunçassem.

Houve uma aula em que levamos diversos tipos de brinquedos: legos (peças de montar), carrinhos, bonecas, brinquedinhos de cozinha (liquidificador, pratinhos, garfos, facas, panelinhas, fogão, frutas de plástico), brinquedinhos de médico, cabeleireiro, entre outros. Espalhamos os brinquedos pela quadra poliesportiva e deixamos as crianças à vontade para escolherem e brincarem com os brinquedos conforme quisessem. Ao observá-los brincando, percebemos a riqueza de sua imaginação, pois os brinquedos davam suporte para a fantasia.

Alguns brincavam de médicos, outros de cozinheiros, outros de caminhoneiros, e outros eram cabeleireiros.

José dizia para seu colega:

- Eu sou um médico, posso ouvir seu coração?

Enquanto isso, outras crianças brincavam de fazer comida, ser caminhoneiro, montar "prédio" com as peças, e outros brincando de cabeleireiro com a professora Judite. Algumas vezes, ela era a cabeleireira e outras vezes era a "cliente" dos alunos.

Com o passar das observações, percebemos que a professora Sara não saía mais para fazer as atividades com seus alunos: algumas vezes, ficava dentro da sala de aula, esperando terminarmos as atividades, e outras vezes saía, mas não participava.

\section{DISCUSSÃO}

Os estudos científicos relacionados à infância têm crescido consideravelmente no campo da Sociologia. Essa abertura no campo sociológico possibilitou o surgimento da Sociologia da Infância, dando um novo olhar à criança, essa que sempre esteve presente na sociedade, porém não era considerada como um sujeito que possui características próprias e que é dotada de 
particularidades. Lima, Moreira e Lima (2014, p. 98) descrevem que "as crianças estavam presentes fisicamente, mas ausentes no que diz respeito à ideia de uma categoria social particular, com especificidades e direitos próprios". A partir disto, trouxemos as contribuições da Sociologia da Infância, para a compreensão da criança como ator social no mundo em que vive.

Somente a partir dos anos de 1980, as pesquisas relacionadas à infância se multiplicaram, e muitas obras, defendendo a criança como produtora de cultura, começaram a surgir. Antes desse período, os temas eram relacionados apenas à educação e à família, e a infância era compreendida de modo passivo e contemplativo (LIMA; LIMA, 2013).

Quinteiro, citado por Oliveira (2008, p. 2), aponta que "pouco se conhece sobre as culturas infantis porque pouco se ouve e pouco se pergunta às crianças [...] há ainda resistência em aceitar o testemunho infantil como fonte de pesquisa confiável e respeitável".

Com isso, a Sociologia da Infância veio desafiar-nos a compreender a capacidade de agência das crianças (PAULA, 2008), e questionar o porquê de elas serem tão ignoradas e marginalizadas pela sociedade, essa que, na maioria das vezes, entende a criança apenas como "imitadora" da cultura instituída pelos adultos.

A Sociologia da Infância tem procurado incluir a criança no contexto social de modo que ela não se torne inferior ao adulto, mas que seja compreendida em suas particularidades. Ela tem o desafio de pesquisar a infância em uma perspectiva interdisciplinar e reconhecer a criança em sua competência, sua participação, e seu protagonismo nas pesquisas, na educação, e em diferentes espaços sociais.

A criança é um ser humano também do hoje que não pode ser limitado ao amanhã, precisa ser compreendida a partir de si mesma e do seu próprio contexto. Representa um sujeito social, que não está passivo em seu processo de socialização, faz história e produz cultura. Esse reconhecimento de ator social ativo é um dos pressupostos básicos propostos pela Sociologia da Infância (Lima, Moreira e Lima, 2014, p. 99-100).

A partir da compreensão da Sociologia da Infância e das culturas infantis, em especial o eixo ludicidade, acredita-se que, por meio do lúdico, a criança satisfaz suas necessidades, seus interesses e seus desejos particulares. Sendo assim, o lúdico é uma das maneiras mais eficazes de envolver os alunos nas atividades, pois a brincadeira é algo específico da criança. Silva e Sena (2010, p. 111), apontam que "[...] o brincar relaciona-se com o prazer. Se brincar é prazer, aprender brincando será um prazer para a criança".

Quando falamos em jogo, brinquedo ou brincadeira, pensamos logo em criança, pois esses pertencem à criança e à infância. Dornelles (p.104, 2001) aponta que "[...] o brincar é uma forma que de linguagem que a criança usa para compreender e interagir consigo, com o outro, com o mundo".

Diante disso, as brincadeiras das crianças deveriam ser concebidas como uma de suas atividades mais sérias. Ao observarmos suas brincadeiras, poderemos entender as crianças, visto que através das brincadeiras elas expressam como veem e constroem o mundo, como gostariam que fosse, o que as preocupam e quais os problemas que a cercam (CAVALARI; CORTEZ, 2010).

O brincar desenvolve de forma natural as habilidades das crianças, não é um simples passatempo. Brincando a criança aprende a socializar-se com outras crianças, desenvolve a motricidade, a mente, a criatividade, sem nenhum tipo de cobrança, medo ou insegurança, mas, sim, com prazer.

Assim, formar professores para introduzir o lúdico na escola é um grande desafio. É fundamental que o educador conceba a riqueza da cultura lúdica infantil e que tenha consciência de que as crianças criam e recriam seu mundo imaginário brincando, o que é essencial em seu desenvolvimento. 


\section{CONCLUSÃO}

O lúdico é um excelente recurso e é indispensável no contexto da Educação Infantil, pois o professor pode utilizá-lo para obter melhores resultados no processo de ensino-aprendizagem e de desenvolvimento infantil. Contudo, esse campo ainda precisa ser ampliado.

Através da brincadeira, o professor pode se aproximar mais da criança, tornando seus momentos um meio de comunicação, de recreação e de prazer, desenvolvendo valores morais, éticos, sociais e cognitivos, e possibilitando a construção de conhecimentos.

É fundamental que o professor considere toda riqueza da cultura lúdica infantil e todo contexto que ela traz consigo para a escola. Faz-se necessário, também, que as professoras aprofundem seus conhecimentos e enriqueçam as experiências lúdicas das crianças no contexto da Educação Infantil para que, assim, elas atinjam seu desenvolvimento pleno de modo eficaz.

A partir dos resultados dessa pesquisa, esperamos ter contribuído para a produção de saberes e pretendemos continuar os estudos, tendo em vista a necessidade de maiores saberes sobre a temática e a importância da ludicidade na vida humana, em especial no desenvolvimento de nossas crianças, pois percebemos que ver e ouvir a criança é de fundamental importância em qualquer pesquisa que deseja estudar a infância e suas culturas.

\section{REFERÊNCIAS}

ANDRÉ, M. E. D. A. Etnografia da prática escolar. 17. ed. Campinas: Papirus, 1995.

CAVALARI, N.; CORTEZ, C. A importância do lúdico na educação infantil. Caderno Multidisciplinar de Pós - Graduação da UCP. Pitanga, v.1, n.3, p. 189-219, mar. 2010.

DORNELLES, L. V. Na escola infantil todo mundo brinca se você brinca. In: CRAIDY, C. M.; KAERCHER, G. E. P. S. (Org). Educação Infantil: pra que te quero? Porto Alegre: Artmed, 2001.

LIMA, M. R. C.; LIMA, J. M. A ludicidade como eixo das culturas da infância. Rev. Interaccções, n.27, p. 207-231, 2013

LIMA, J. M.; MOREIRA, T. A.; LIMA, M. R. C. A sociologia da infância e a educação infantil: outro olhar para as crianças e suas culturas. Rev. Contrapontos, v 14, n. 1, p. 95-110, 2014. https://doi.org/10.14210/contrapontos.v14n1.p95-110

MARCHI, R. C. O "ofício de aluno" e o "ofício de criança": articulações entre a sociologia da educação e a sociologia da infância. Rev. Portuguesa de Educação, v. 23, n.1, p. 183-202 2010. https://doi.org/10.21814/rpe.13983

OLIVEIRA, F. Sociologia da Infância. Rev. Sociologia. Disponível em: <http://sociologiacienciaevida.uol.com.br/ESSO/Edicoes/17/artigo92128-2.asp>. Acesso em: 09 jan. 2014

PAULA, E. Novos murmúrios sobre as metodologias de pesquisa com crianças pequenas: desafios e rupturas. Contrapontos, v. 8, n.1, p.131-146 - Itajaí, jan/abr 2008.

SANDÍN ESTEBAN, P. P. Pesquisa qualitativa em educação: fundamentos e tradições. Porto Alegre: AMGH, 2010.

SILVA, J. A.; SENA, S. S. A importância do lúdico na Educação Infantil: fundamentação teórica. Caderno Multidisciplinar de Pós - Graduação da UCP. Pitanga, v.1, n.1, p. 106-121, jan 2010. 
VIÉGAS, L. S. Reflexões sobre a pesquisa etnográfica em Psicologia e Educação. Salvador, jan/junho 2007. 